\title{
METABOLIC STUDIES WITH A NEW SERIES OF 1,4-DIENE STEROIDS. II. EFFECTS IN NORMAL SUBJECTS OF PREDNISONE, PREDNISOLONE, AND $9 \alpha$-FLUOROPREDNISOLONE *
}

By MAURICE M. PECHET, $\dagger$ BLAIR BOWERS $\ddagger$ AND FREDERIC C. BARTTER

(From the Clinic of General Medicine and Experimental Therapeutics, National Heart Institute, National Institutes of Health, Bethesda, Md.)

(Submitted for publication May 13, 1958; accepted December 4, 1958)

1,2-Dehydrogenation of 21-carbon steroids possessing an oxygen function at carbons 11,17 and 21 (cortisone and cortisol) results in an enhancement of anti-anabolic or catabolic and anti-inflammatory properties in Addisonian subjects (2).

* Part of this material has been presented previously (1). The names "metacortandracin" and "metacortandralone" have since been replaced by "prednisone" and "prednisolone."
The present study was undertaken to extend these observations to normal subjects and to delineate further the effects of these steroids, in very large doses, on the constituents of protoplasm.

$\dagger$ Present address : Medical Service, Massachusetts General Hospital, Boston, Mass.

$¥$ Present address: Harvard University, Cambridge, Mass.

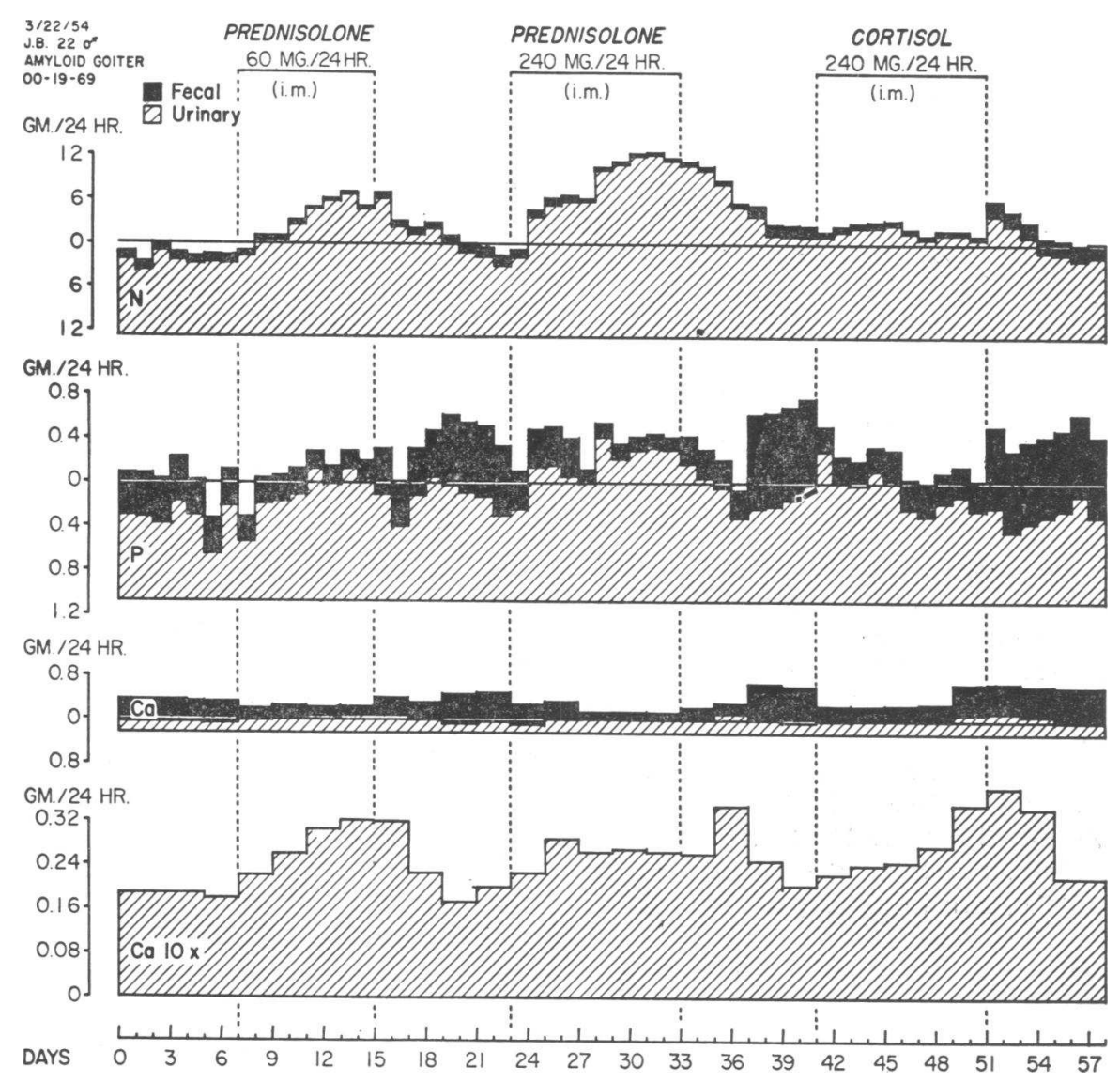

Fig. 1. The Effect of 1,4-Diene Steroids and the Parent Compounds on Nitrogen, Phosphorus and Calcium Balances in J. B.

Balance data in this and subsequent charts are plotted as follows: Intake is plotted downwards from the 0 line, urinary values are plotted upwards from the intake line, and fecal values are superimposed on them. Thus, positive balance is indicated by a clear area below the 0 line, and negative balance by a shaded area above it. 


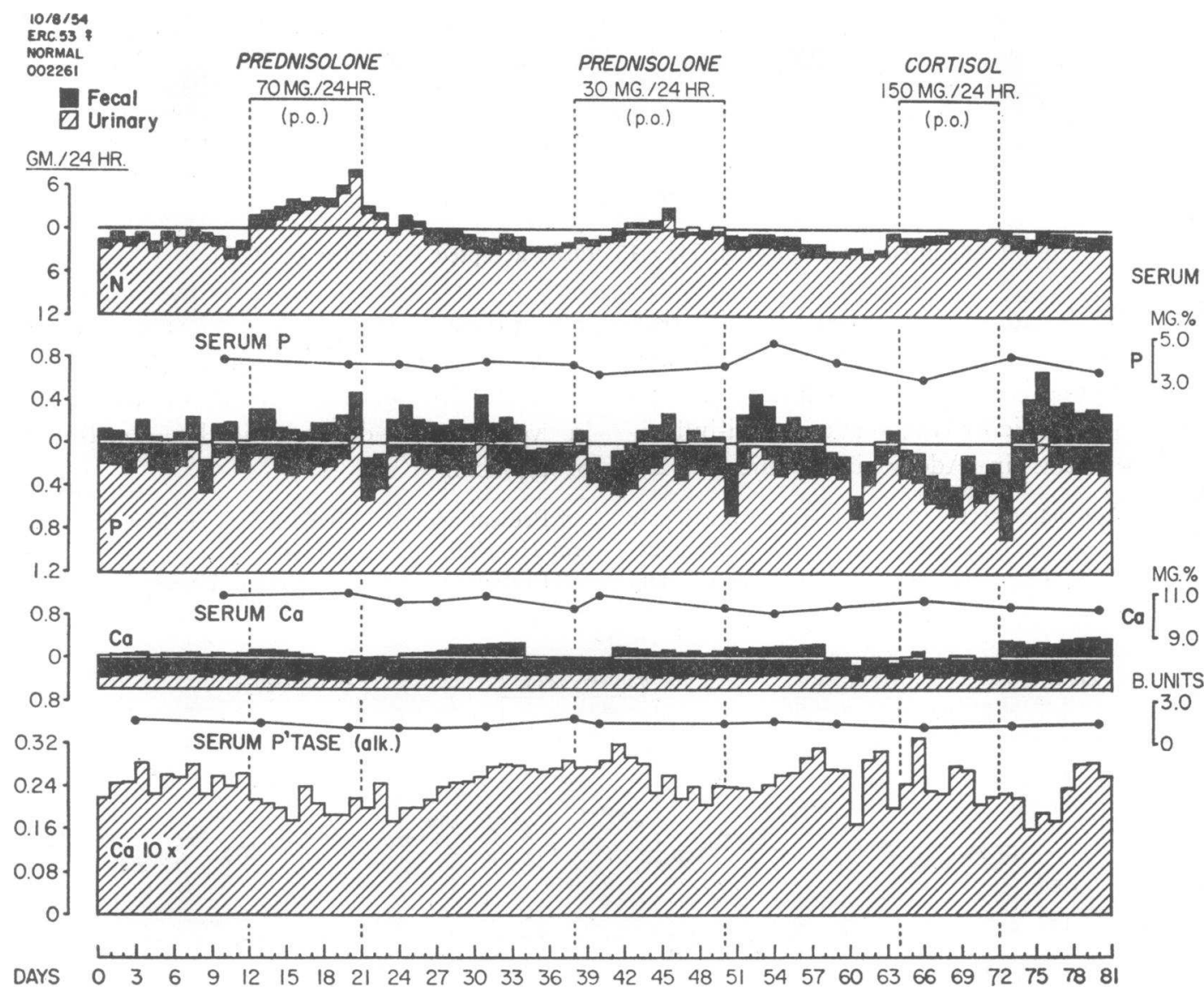

Fig. 2. The Effect of 1,4-Diene Steroids and the Parent Compounds on Nitrogen, Phosphorus and Calctum Balances, Serum Phosphorus, Calcium and Alkaline Phosphatase in E. C.

\section{METHOD}

Balance studies were carried out on three normal subjects. The diet and fluid intake were kept constant. Stools were collected in six or eight day periods and urine in one day pools. Stools, diets and urine were analyzed for nitrogen (3), phosphorus (4), calcium (5), potassium and sodium (6). Urine was also analyzed for 17,21-dihydroxycorticoids (phenylhydrazine-sulfuric acid chromogens) (7) and 17-ketosteroids (8). Blood was drawn at appropriate intervals for the determination of circulating eosinophiles, serum sodium, potassium, carbon dioxide, calcium and phosphorus. Steroids were given orally or intramuscularly, one-quarter of the dose every six hours.

\section{RESULTS}

The results are shown graphically in Figures 1 through 11.

During treatment with both the 1,4-diene steroids and the parent compounds the fecal excretion of nitrogen, phosphorus, calcium and potas- sium was generally less than that in the preceding control periods; after treatment it was generally much greater. The patients complained of constipation during treatment. The large fluctuations in apparent calcium and phosphorus balances resulting from this phenomenon (see, for example, Figures 1 and 2) render balance data relatively less reliable than urinary data for these elements.

\section{Nitrogen metabolism}

Prednisolone, in doses of $30 \mathrm{mg}$. a day, caused an increase in urinary nitrogen excretion and a slight negative nitrogen balance (Figure 2). The loss of nitrogen at this dosage was only slightly greater than that with the parent steroid, cortisol, at five times the dose. Prednisone and prednisolone, in doses of $70 \mathrm{mg}$. a day administered orally, caused a marked increase in urinary nitrogen ex- 


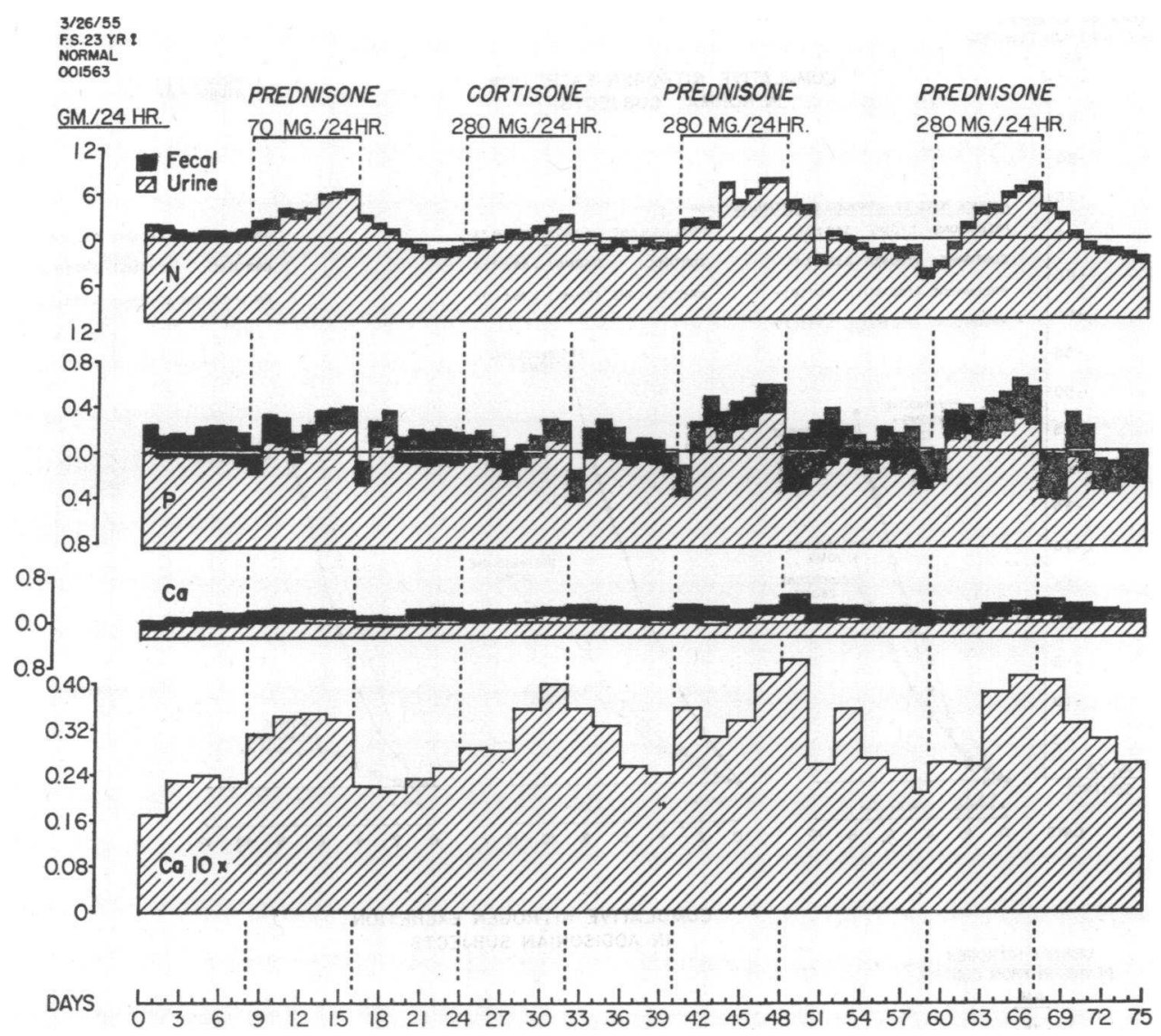

Fig. 3. The Effect of 1,4-Diene Steroms and the Parent Compounds on Nitrogen, Phosphorus and Calcium Balances in F. S.

cretion and a negative nitrogen balance (Figures 2 and 3 ). The loss of nitrogen induced by 70 mg. of the 1,4-diene steroids was considerably greater than that with the parent steroids, cortisol and cortisone, at doses two to five times as large. Prednisone, in doses of $280 \mathrm{mg}$. a day, caused a large increase in urinary nitrogen and a negative nitrogen balance (Figure 3). The loss of nitrogen at this dosage was greater than that with cortisone at the same dosage. The loss of nitrogen, with 60 and $240 \mathrm{mg}$. of prednisolone administered intramuscularly (Figure 1), was similar in magnitude to that caused by 70 and $280 \mathrm{mg}$. of the 1,4-diene steroids administered orally (Figures 2 and 3 ), but persisted for longer periods following the termination of therapy. The effects of the 1,4-diene steroids and the parent compounds on mitrogen excretion are summarized in Figure 4. As judged from the effects on nitro- gen balance, prednisone and prednisolone, administered orally, appear from these studies to be seven to eight times [parallel line assay method (9) ] as active as the parent steroids. The effects on nitrogen metabolism of both types of steroids are quantitatively more pronounced in the Addisonian than in the normal subjects (Figure 4). 9 $\alpha$-Fluoroprednisolone and the parent compound, $9 \alpha$-fluorocortisol, in doses of $3 \mathrm{mg}$. a day, did not affect nitrogen metabolism (Figure 5).

\section{Phosphorus metabolism}

Prednisolone, at a dose of $30 \mathrm{mg}$. a day, had little effect on phosphorus metabolism (Figure 2). The slight apparent negative phosphorus balance seen with this treatment did not differ from that found throughout these studies. Prednisone and prednisolone, in doses of 60 to 280 


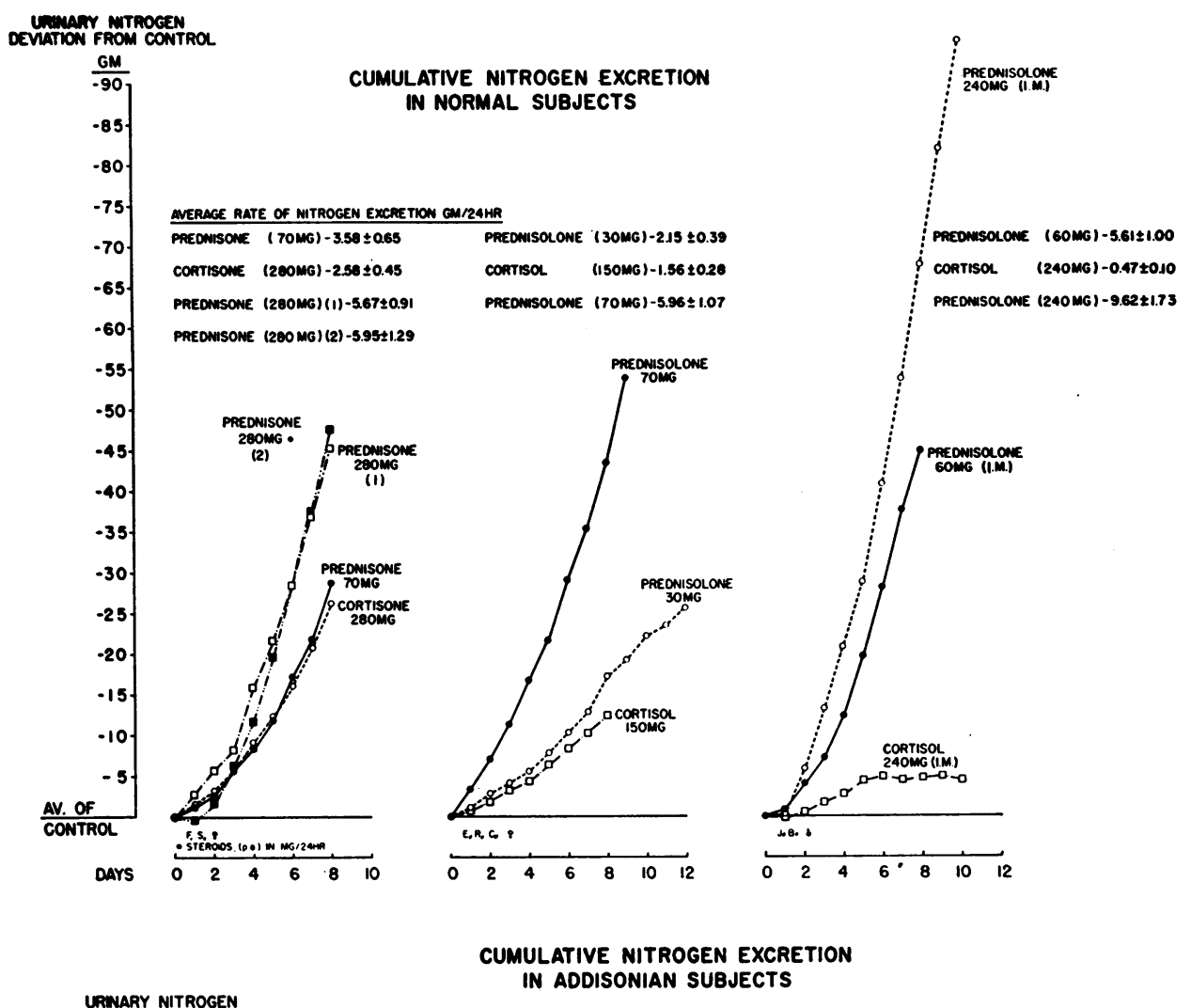

URINARY NITROGEN
DEVIATION FROM CONTROL
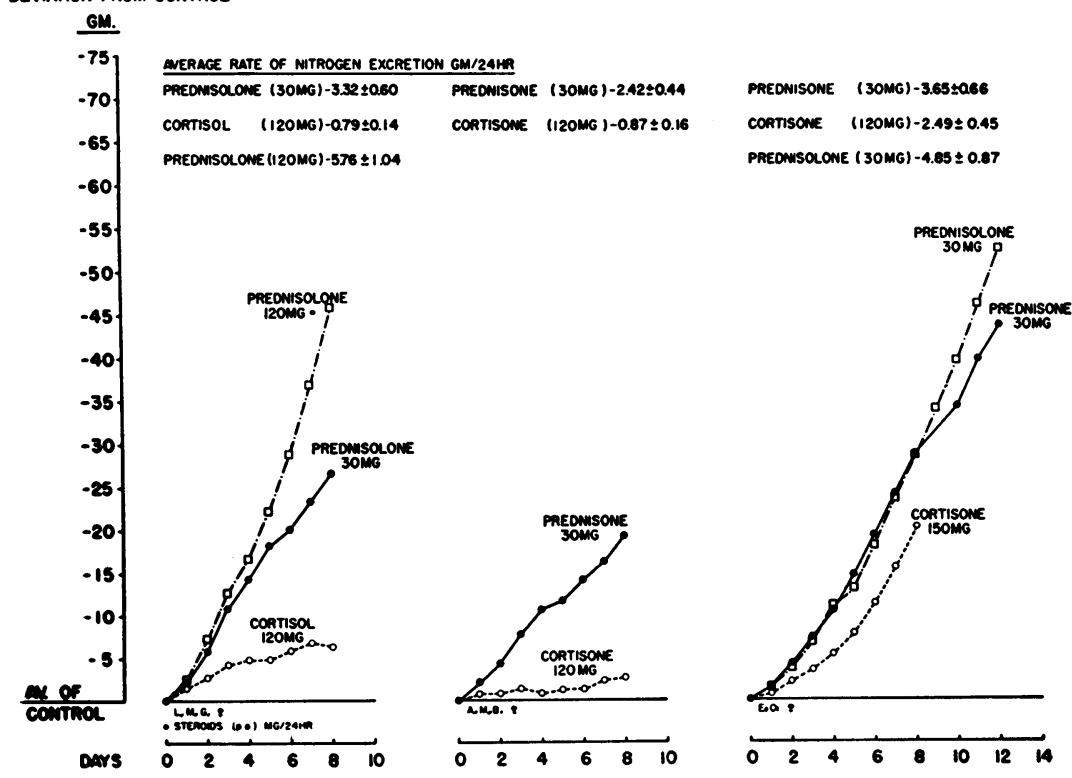

Fig. 4. The Effect of 1,4-Diene Steroids and the Parent Compounds on Nitrogen Excretion, Expressed as the Mean Daily Difference Between Treatment and Control. PERIODS

The daily deviation from control is plotted cumulatively. Comparable results for three Addisonian subjects are included for comparison. The daily average rate of nitrogen excretion has been determined from the linear regression (9). 


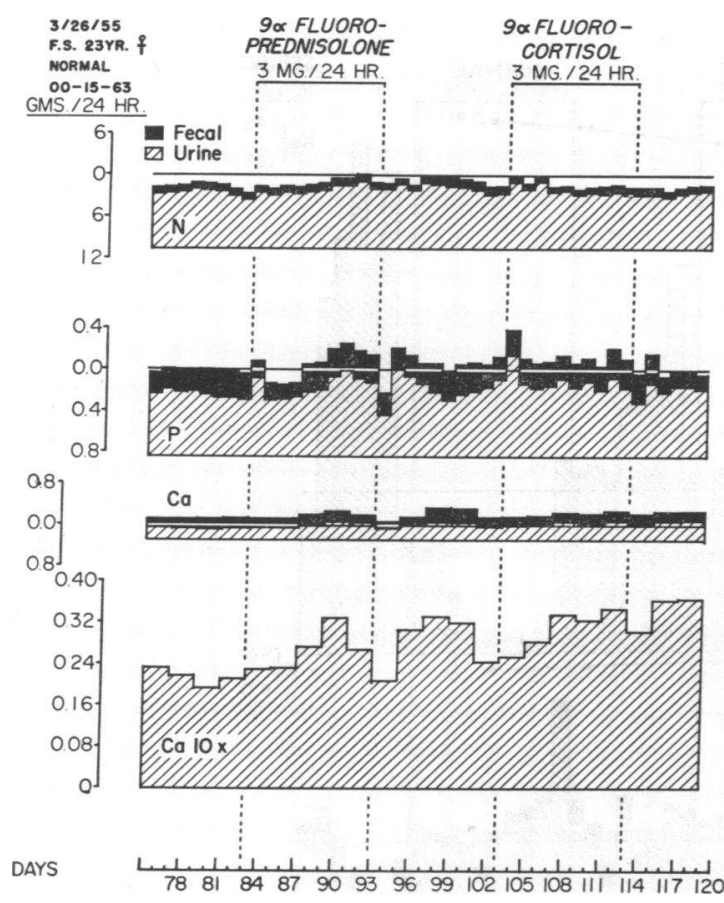

Fig. 5. The EFFECT of 9 $\alpha$-Fluoroprednisolone AND the Parent Compound on Nitrogen, Phosphorus and Calcium Balances in F. S.

mg. a day, caused an increase of urinary phosphorus which was not apparent until the second day of medication (Figures 1 and 3 ). Indeed, in three instances urinary phosphorus fell on the first day. In all instances urinary phosphorus fell promptly after treatment was stopped. Cortisone and cortisol, in doses of 150 to $280 \mathrm{mg}$. a day, caused a decrease in urinary phosphorus in two instances and no change in the third: The increase in negative phosphorus balances seen with the 1,4-diene steroids was not seen with the parent compounds. Even when considerable phosphorus loss was produced by the 1,4-diene steroids, it was disproportionately small compared to the nitrogen loss $(10,11)$.

\section{Calcium metabolism}

Prednisolone, at a dose of $30 \mathrm{mg}$. a day, had little effect on calcium metabolism (Figure 2). The slight apparent negative calcium balance with this medication did not differ from that found throughout these studies. Prednisone and prednisolone, in doses of 60 to $280 \mathrm{mg}$. a day, caused an increase of urinary calcium in five of the six periods studied (Figures 1 and 3) with return to control values in one day after oral medication and in two to three days after intramuscular medication. In the remaining period, urinary calcium fell during the treatment (Figure 2). With cortisone and cortisol, in doses of 240 and $280 \mathrm{mg}$. a day, there was an increase in urinary calcium with a subsequent fall on withdrawal of medication (Figures 1 and 3). With cortisol, at a dose of $150 \mathrm{mg}$. a day, urinary calcium did not change significantly (Figure 2). With $9 \alpha$-fluoroprednisolone and $9 \alpha$-fluorocortisol, in doses of $3 \mathrm{mg}$. a day, there was a rise of urinary calcium (Figure 5).

\section{Potassium metabolism}

Prednisone and prednisolone, in doses of 30 to $280 \mathrm{mg}$. a day, caused transient increases of urinary potassium, with negative balance, on the first day of treatment (Figures 6 through 8). When treatment was discontinued, there was a transient decrease of urinary potassium, with positive balance, for one to three days. The same changes occurred with cortisone and cortisol in doses of 150 to $280 \mathrm{mg}$. a day (Figures 6 through 8). In no instance were the changes in potassium balance accompanied by commensurate changes in nitrogen balance: They occurred even when there were no reciprocal changes in sodium balance.

$9 \alpha$-Fluoroprednisolone and $9 \alpha$-cortisol, in doses of $3 \mathrm{mg}$. a day, caused similar marked transient increases of urinary potassium, with negative balance, on the first day of treatment (Figure 9). On the fourth subsequent day there occurred a second rise in the urinary potassium, with negative balance, which persisted until withdrawal of treatment: The serum potassium fell markedly with both steroids. A prompt decrease of urinary potassium, with positive balance, occurred when treatment was discontinued. These latter periods of negative and positive balance were associated with reciprocal changes in sodium balance (vide infra).

\section{$V$. Sodium metabolism}

Prednisone and prednisolone, in doses of 30 to $70 \mathrm{mg}$. a day, produced increases in urinary sodium with negative sodium balance. In two in- 


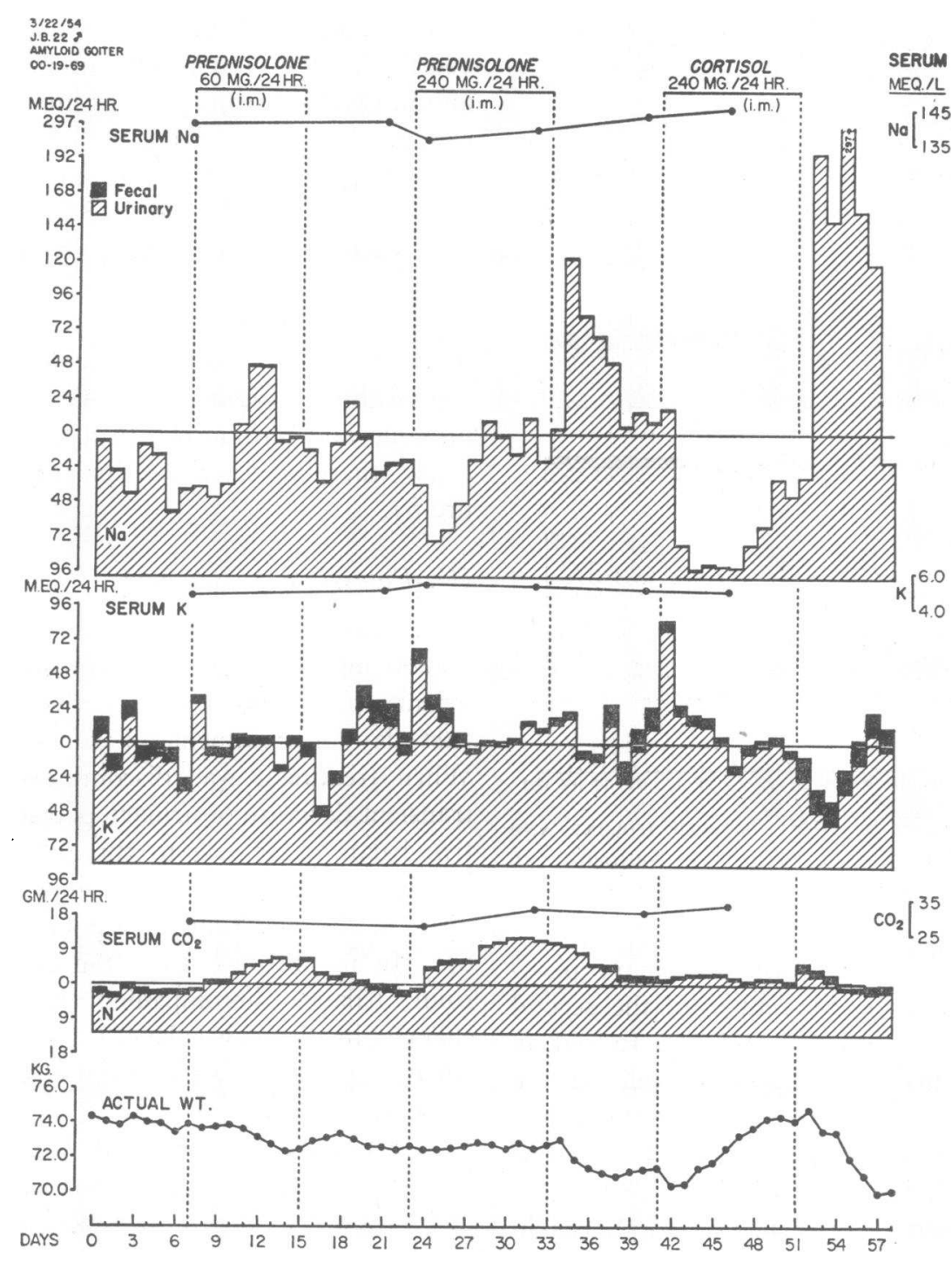

Fig. 6. The Effect of 1,4-Diene Steroms and the Parent Compounds on Sodium, Potassium and Nitrogen Balances, Serum Sodrum, Potassium, Carbon Dioxide and Body Weight in J. B.

stances this did not occur until the fifth day of treatment: In one it was preceded by slight sodium retention (Figures 6 through 8 ). In doses of 240 to $280 \mathrm{mg}$. a day, prednisone and prednisolone caused sodium retention which did not persist beyond the fourth day and was, in one instance, followed by significant sodium loss despite continued treatment (Figures 6 and 8 ). The effect of doubling the sodium intake on the response to $280 \mathrm{mg}$. of prednisone is shown in Figure 8 . On the higher sodium intake the early retention and the late loss of sodium were quantitatively much greater.

Cortisone and cortisol, in doses of 150 and 280 mg. a day, produced quantitatively much greater retention of sodium and allowed relatively little "escape" during therapy (Figures 6 and 8).

$9 \alpha$-Fluoroprednisolone and $9 \alpha$-fluorocortisol, in doses of $3 \mathrm{mg}$. a day, caused marked sodium retention (Figure 9), which was accompanied (vide supra) by potassium loss and hypokalemia. Quantitatively, the effects of the two steroids 


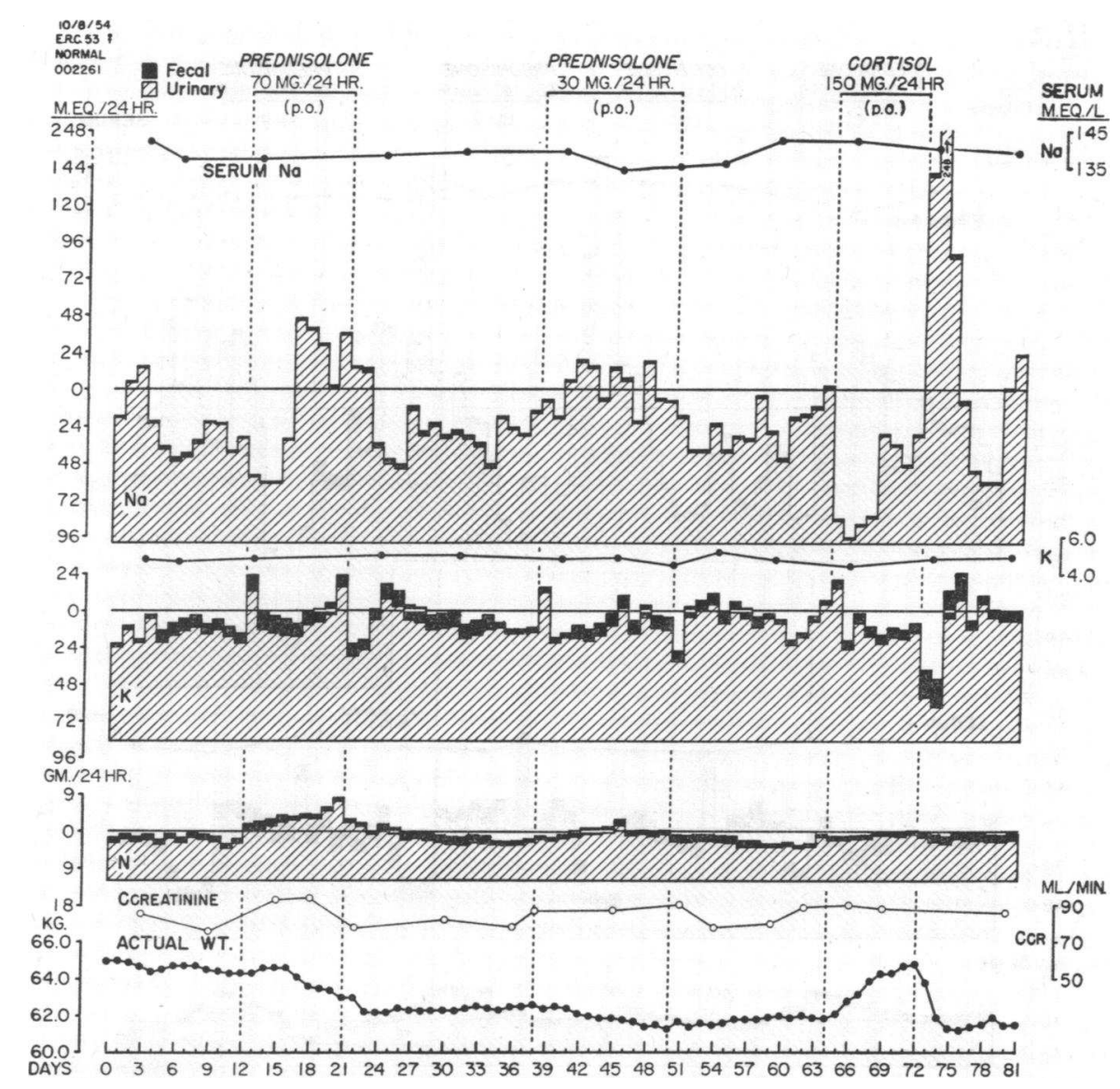

Fig. 7. The Effect of 1,4-Diene Steroids and the Parent Compounds on Sodium, Potassium and Nitrogen Balances, Serum Sodium, Potassium, Creatinine ClearANCE ANd Body Weight in E. C.

were comparable. In both cases there was partial "escape" from the sodium-retaining effect with continued therapy.

\section{17-Ketosteroids}

In a dose of $30 \mathrm{mg}$. a day, prednisolone caused a slow decrease in urinary 17 -ketosteroid excretion, followed by a prompt return to control values after treatment was stopped (Figure 10). At a dose of $70 \mathrm{mg}$. a day, it caused a prompt decrease in urinary 17-ketosteroid excretion, followed by a slow return to control values. At a dose of $150 \mathrm{mg}$. a day, cortisol caused a transient decrease in urinary 17 -ketosteroids, followed by an increase despite continued treatment. After treatment was stopped, urinary 17 -ketosteroid excretion decreased to values comparable to those observed during treatment with the 1,4-diene steroids.

\section{Theoretical weight curves}

"Theoretical" weight curves based on nitrogen, potassium and sodium balances are presented in Figures 8 and 9. They show excellent correlation with the actual weight curves indicating that there were no unexplained shifts of fluid during these studies.

\section{DISCUSSION}

The loss of nitrogen produced by the 1,4-diene steroids and the parent compounds is shown in summary in Figure 4. It is clear that the potency of prednisone and prednisolone, judged from their effects upon nitrogen metabolism, is considerably 


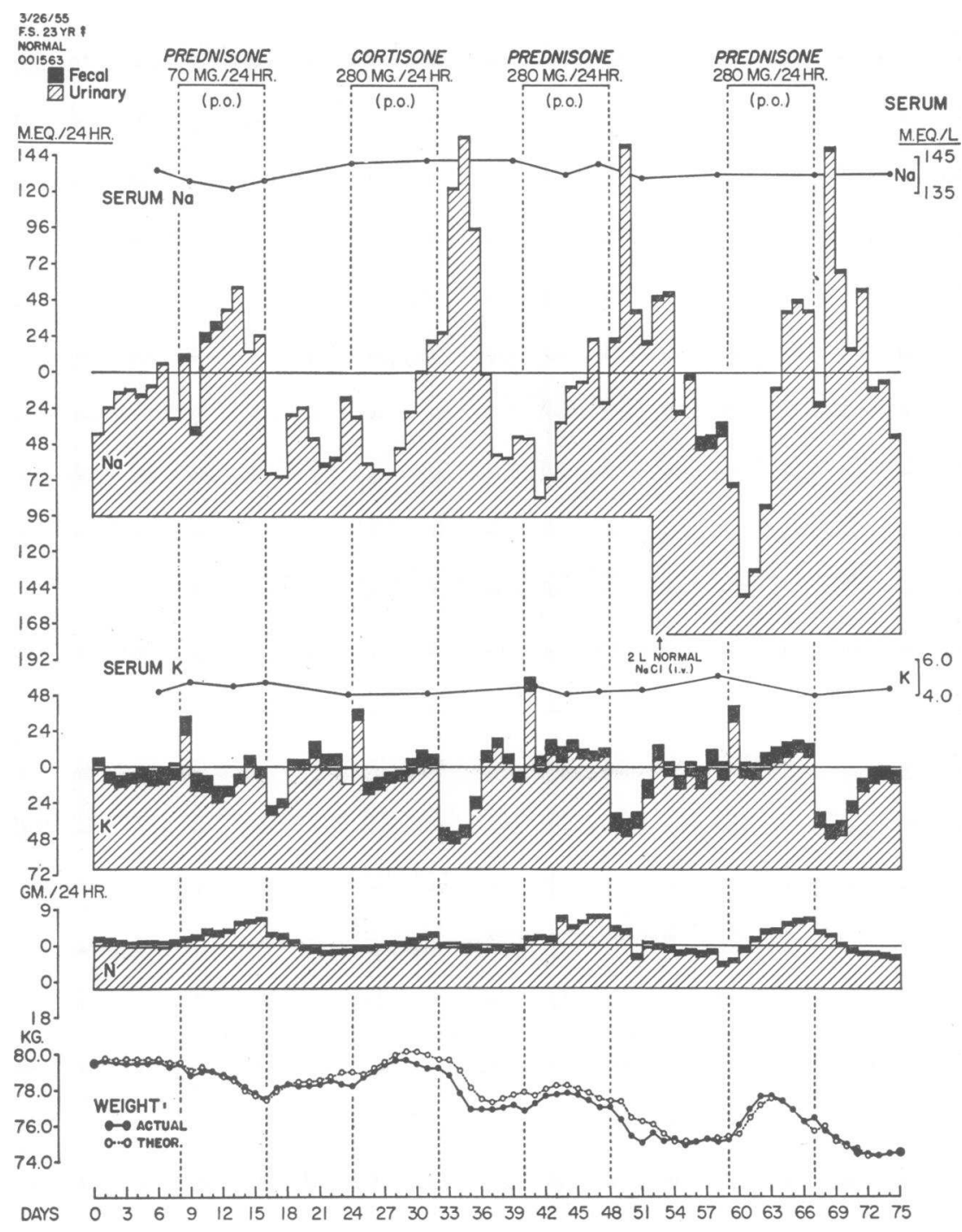

Fig. 8. The Effect of 1,4-Diene Steroids and the Parent Compounds on Sodium, Potassium and Nitrogen Balances, Serum Sodium, Potassium and Actual and "Theoretical" Body Weight in F. S.

more than four times that of the parent compounds, the factor (12) estimated from anti-inflammatory effects in rheumatoid arthritis. Indeed, the mean ratio of potency of 1,4-diene to parent steroids based upon these studies on nitrogen metabolism is about eight. This is somewhat lower than the ratio (about 12) arrived at from studies on Addisonian patients (2).

In spite of the fluctuations in apparent calcium balance previously alluded to (and ascribed to the constipating effect of the steriods), it is evident from the magnitude of the increases of urinary calcium seen with the 1,4-diene steroids at the higher doses that they represent loss of bone tissue.

The effect of these steroids on potassium metabolism appears to represent the summation of four independent phenomena. a) The transient loss of potassium on starting treatment, which precedes nitrogen loss and sodium retention, and the corresponding transient retention of potassium on stopping treatment, which precedes nitrogen retention and sodium loss (see, for example, Figure 8 , Days 8 and 16, 40 and 48), has been attributed to the anti-inflammatory action of steroids 
(13). b) When large losses of nitrogen were induced with the steroids, some loss of potassium also occurred (see, for example, Figure 6, Days 30 to 33). However, in no instance was the magnitude of the loss commensurate (10) with that of nitrogen. This strongly suggests that $c$ ) potassium without nitrogen was stored during steroid administration. As noted above, a similar discrepancy appeared in the phosphorus balance, and both may be attributable to glycogen formation. Finally, $d$ ) with halogenated steroids, in doses too small to affect nitrogen balance, large losses of potassium were seen when sodium was being retained, and large gains of potassium were seen when sodium was lost after the steroids were discontinued (see, for example, Figure 9). This phenomenon appears to result from steroid-induced potentiation of sodium-potassium exchange at the renal tubular level $(14,15)$.

This study confirms the impression gained from an earlier one (2) that the 1,4-diene steroids increase renal tubular sodium transport, as they produced transient sodium retention when given in large doses. The subsequent "escape," which we attribute to enhancement of glomerular filtration rate, occurred in all instances.

The suppression of adrenal cortical activity of the 1,4-diene steroids is apparent from the marked decrease in 17-ketosteroid excretion (Figure 10). With cortisol, at two to five times the dose, only transient decrease of 17 -ketosteroid excretion occurred. The difference appears to be the resultant of two phenomena. At the doses employed, both prednisolone and cortisol probably suppress adrenocorticotropic hormone (ACTH) secretion equally effectively. Consequently, secretion of adrenal 19-carbon steroids, as well as that of 21carbon steroids destined for degradation to 19carbon steroids, is suppressed. The urinary 17ketosteroids during therapy (in this female subject) presumably represent degradation products of the administered steroid. The low figures observed with the 1,4-diene steroids result both from the enhanced ability of these steroids to suppress the adrenal cortex and from their limited conversion to 17 -ketosteroids, as compared to the parent steroids (16). The latter phenomenon is illustrated in Figure 11, which shows studies in a female Addisonian subject lacking endogenous sources of 17 -ketosteroids.

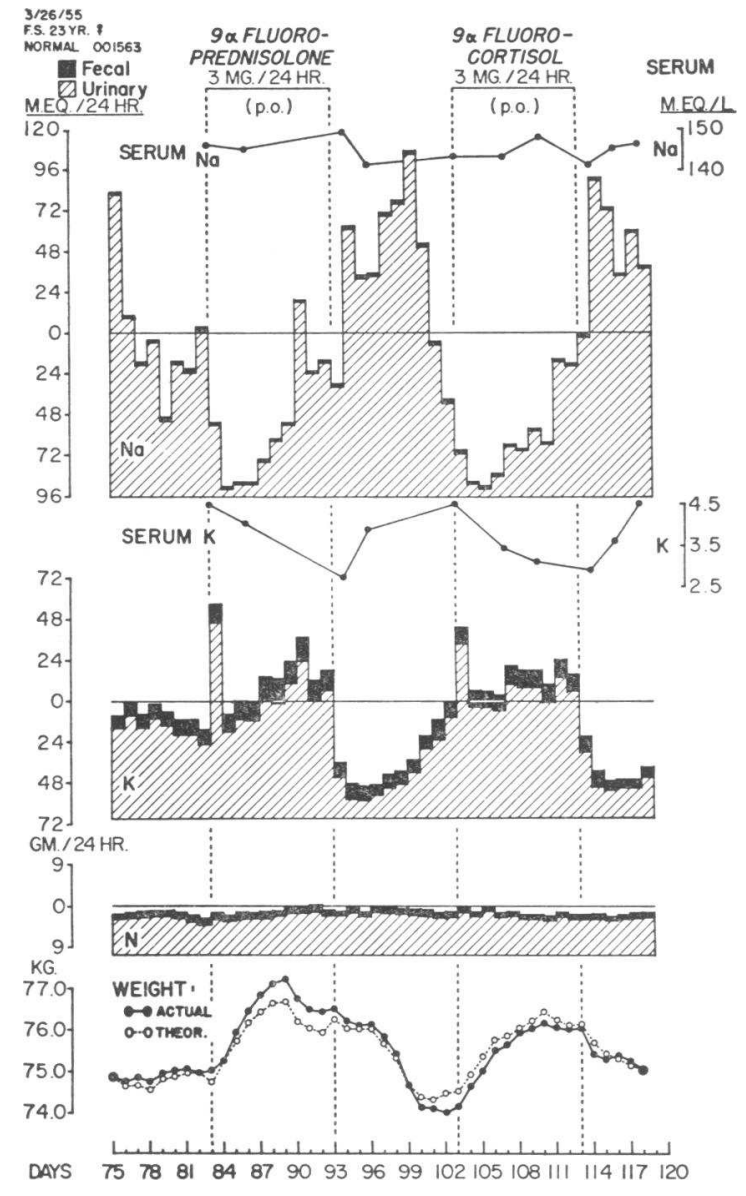

Fig. 9. The EFfect of 9 $\alpha$-Fluoroprednisolone and the Parent Compound on Sodium, Potassium and Nitrogen Balances, Serum Sodium, Potassium and Actual and "Theoretical” Body Weight in F. S.

\section{SUMMARY}

The effect of unsaturation by 1,2-dehydrogenation on the activity of 21-carbon steroids, given in moderate and very large doses, was explored with balance studies and steroid analyses in three subjects with normal adrenal cortical function. Unsaturation at carbon 1-2 results in an increase of anti-anabolic or catabolic activity which, judged from nitrogen loss, was some eight times that of the parent steroids. In the large doses, the unsaturated steroids produced sodium loss only after transient sodium retention. Unsaturation enhanced the ability of the parent compounds to suppress urinary 17-ketosteroids, decreasing their susceptibility to oxidative cleavage to 17 -ketosteroids. 


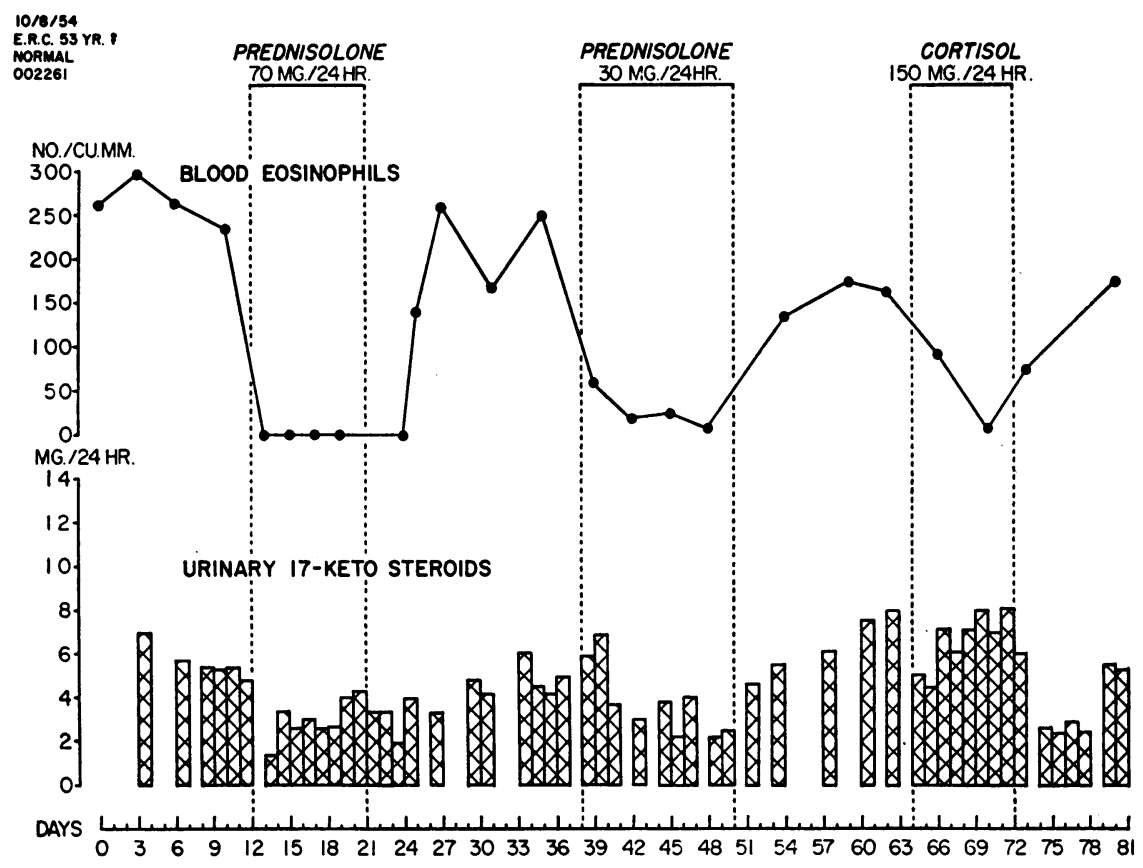

Fig. 10. The Effect of 1,4-Diene Steroids and the Parent Compounds on Circulating Blood Eosinophiles and Urinary 17-Ketosteroids in E. C.

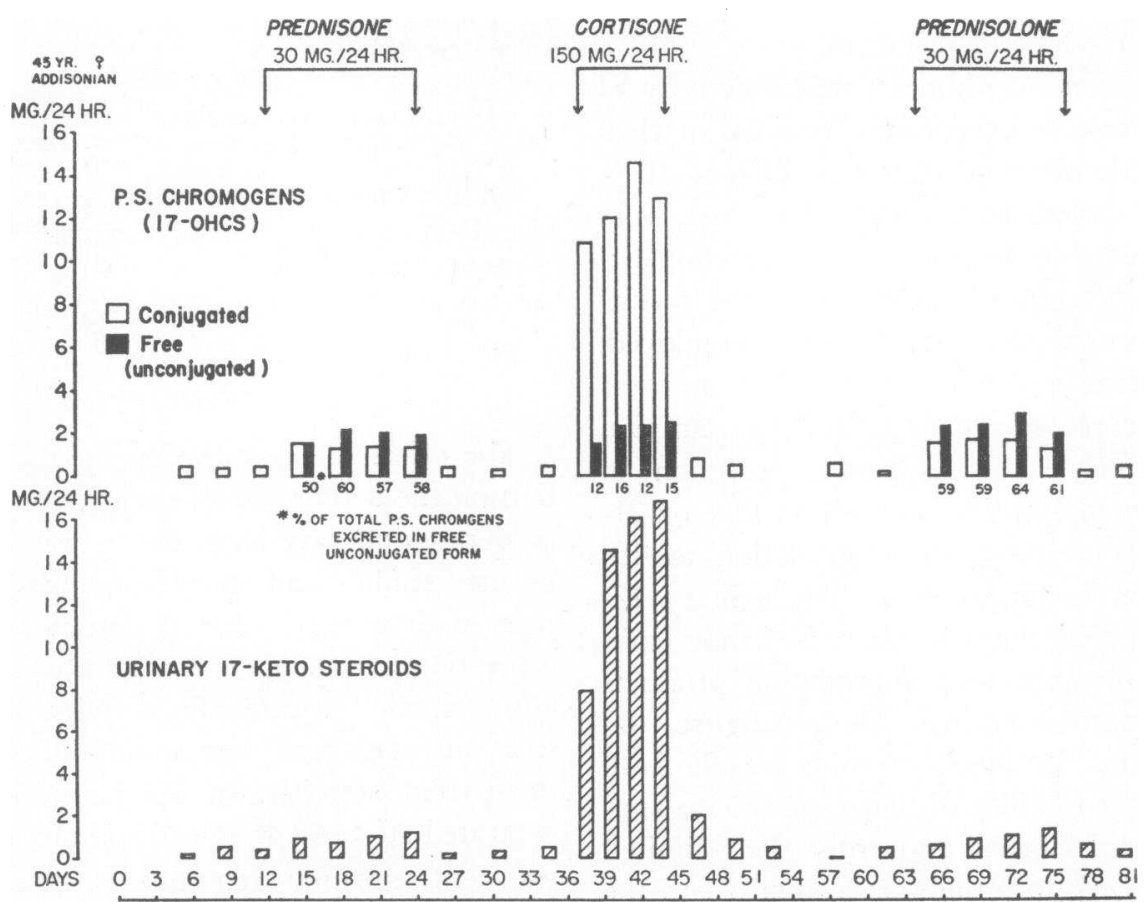

Fig. 11. The Effect of 1,4-Diene Steroids and the Parent Compound on Urinary Free and Conjugated Phenylhydrazine-Sulfuric Act Chromogens and on Urinary 17-Ketosteroids in a Patient with Addison's Disease 


\section{REFERENCES}

1. Pechet, M. M. The metabolic effects of metacortandracin and metacortandralone in man: A new series of $\Delta^{1,4}$-diene steroids. J. clin. Invest. 1955, 34, 913.

2. Pechet, M. M., Bowers, B., and Bartter, F. C. Metabolic studies with a new series of 1,4-diene steroids. I. Effects in Addisonian subjects of prednisone, prednisolone, and the 1,2-dehydro analogues of corticosterone, desoxycorticosterone, 17-hydroxy11-desoxycorticosterone, and $9 \alpha$-fluorocortisol. J. clin. Invest. 1959, 38, 681.

3. Folin, O. Laboratory Manual of Biological Chemistry, 5th ed. New York, Appleton-Century Co., Inc., 1934.

4. Fiske, C. H., and Subbarow, Y. The colorimetric determination of phosphorus. J. biol. Chem. 1925, $66,375$.

5. Fiske, C. H., and Logan, M. A. Determination of calcium by alkalimetric titration. II. Precipitation of calcium in the presence of magnesium, phosphate, and sulfate with applications to analysis of urine. J. biol. Chem. 1931, 93, 211.

6. Berry, J. W., Chappell, D., and Barnes, R. B. Improved method of flame photometry. Industr. engin. Chem. (Analyt. Ed.) 1946, 18, 19.

7. Silber, R. H., and Porter, C. C. The determination of 17,21-dihydroxy-20-ketosteroids in urine and plasma. J. biol. Chem. 1954, 210, 923.

8. Hamburger, C. Micro-methods for the determina- tion of 17 -ketosteroids in urine. Acta Endocr. 1948, 1, 375.

9. Finney, D. J. Statistical Method in Biological Assay. New York, Hafner Publishing Co., 1952.

10. Reifenstein, E. C., Jr., Albright, F., and Wells, S. L. The accumulation, interpretation, and presentation of data pertaining to metabolic balances, notably those of calcium, phosphorus, and nitrogen. J. clin. Endocr. 1945, 5, 367.

11. Bartter, F. C., Fourman, P., Albright, F., Forbes, A. P., Jefferies, W. M., Griswold, G., Dempsey, E., Bryant, D., and Carroll, E. The effect of adrenocorticotropic hormone in panhypopituitarism. J. clin. Invest. 1950, 29, 950.

12. Bunim, J. J., Pechet, M. M., and Bollet, A. J. Studies on metacortandralone and metacortandracin in rheumatoid arthritis. J. Amer. med. Ass. 1955, 157, 311.

13. Bartter, F. C., and Fourman, P. A non-renal effect of adrenal cortical steroids upon potassium metabolism (abstract). J. clin. Invest. 1957, 36, 872.

14. Berliner, R. W. Renal secretion of potassium and hydrogen ions. Fed. Proc. 1952, 11, 695.

15. Bartter, F. C. The role of aldosterone in normal homeostasis and in certain disease states. $\mathrm{Me}-$ tabolism 1956, 5, 369.

16. Pechet, M. M., and Claffey, J. The metabolic conversion in man of 21-carbon and 19-carbon-1,4diene steroids to 17 -ketosteroids. Clin. Res. Proc. 1957, 5, 191. 